\title{
GERENCIAMENTO DE RESÍDUOS DE ENSAIOS QUÍMICOS DE SOLO E PLANTA NO CENTRO NACIONAL DE PESQUISA DE ARROZ E FEIJÃO (CNPAF)
}

\author{
Diego Mendes de Souza* \\ Demétrio Santana Medeiros** \\ Ivã Matsushige ${ }^{* * *}$ \\ Wesley Gabriel de Oliveira Leal ${ }^{* * *}$ \\ Roberto Carlos Gomes dos Santos*** \\ Larissa Almeida de Oliveira**** \\ Pedro Augusto de Oliveira Morais**** \\ Loyane Mendes de Souza ${ }^{* * * * * *}$
}

RESUMO: Este trabalho relata o gerenciamento de resíduos sólidos gerados nas análises de solo e planta do Laboratório de Análise Agroambiental (LAA) do Centro Nacional de Pesquisa de Arroz e Feijão (CNPAF) como experiência única da bibliografia nacional por englobar conjuntamente: identificação dos riscos toxicológicos, descrição da composição química, classificação, redução da geração e tratamento dos resíduos. Por isso, esse gerenciamento de resíduos sólidos está em consonância com a Política Nacional de Resíduos Sólidos - PNRS (Lei n ${ }^{\circ} 12.305$, de 2010). Detalham-se a origem, toxicidade e tratamento dos resíduos tóxicos do LAA e as medidas adotadas para diminuição do passivo ambiental gerado. Os resíduos desse laboratório advêm das análises químicas de solo e tecido vegetal, dentre os quais se destacam pela toxicidade: o cianeto que é tratado por oxidação a gás carbônico; e o cromo que é tratado por precipitação, reduzindo seu volume em 90\%. O LAA avaliou ainda a possibilidade de reciclagem ou reutilização como pigmento cerâmico do resíduo contendo cromo. O LAA destaca-se por aplicar de forma eficaz a PNRS, mas os resultados apontam necessidade de automatização para viabilizar a reciclagem ou reutilização dos resíduos.

PALAVRAS-CHAVE: PNRS; Redução da geração; Tratamento.

Centro Nacional de Pesquisa de Arroz e Feijão da Empresa Brasileira de Pesquisa Agropecuária (EMBRAPA), Brasil; E-mail: diego.souza@embrapa.br

** Instituto Federal de Goiás (IFG), Brasil.

*** Centro Nacional de Pesquisa de Arroz e Feijão da Empresa Brasileira de Pesquisa Agropecuária (EMBRAPA), Brasil.

***** Instituto Federal de Goiás (IFG), Brasil.

***** Doutorando em Química pela Universidade Federal de Goiás (UFG), Brasil.

****** Companhia de Saneamento Ambiental do Distrito Federal (CAESB), Brasil. 


\section{MANAGEMENT OF CHEMICAL ASSAY WASTES FROM SOIL AND PLANTS IN THE NATIONAL RESEARCH CENTER FOR RICE AND BEANS (CNPAF)}

ABSTRACT: Current research reports on the management of solid wastes produced in soil and plant analyses at the Laboratory of Agro-environmental Analysis (LAA) of the National Research Center for Rice and Beans (CNPAF) as a single experience in Brazilian bibliography. The latter comprises identification of toxological risks, description of chemical composition, classification, reduction of generation and treatment of wastes. Management of solid wastes complies with the Brazilian Policy for Solid wastes - PNRS (Law 12305 published in 2010). The origin, toxicity and treatment of LAA toxic wastes and measures adopted for the reduction of the environmental produce generated are detailed. Residues from the laboratory derive from chemical analyses of soil and vegetal tissues, with special toxic rates: cyanide treated with carbonic gas oxidation and chromium treated by precipitation with $90 \%$ reduction. LAA evaluated the possibility of recycling or reutilization such as the ceramic pigment of the waste with chromium. LAA is important because it applies PNRS efficiently even though results require automatization to make viable the recycling or reutilization of wastes.

KEY WORDS: PNRS; Reduction of Produce; Treatment.

\section{INTRODUÇÃO}

O Brasil tem importante papel como um dos líderes na responsabilidade ambiental. A população é parte tocante no tema, pela sua sensibilidade a desastres ambientais e pelo seu anseio à legislação mais rígida. Contudo, institucionalizar o dever ambiental é imprescindível, uma vez que direciona deveres e responsabilidades às empresas e ao poder público, sendo um dos principais temas da Rio + 20 (MACÊDO, 2006; ONU, 2013). A administração pública é agente fiscalizador e também atua na educação ambiental durante a formação básica e acadêmica. Contudo, o Estado pode ser também agente poluidor, principalmente quando explora atividades econômicas, como no caso das empresas públicas, a exemplo da Empresa Brasileira de Pesquisa Agropecuária (Embrapa) e das sociedades de economia mista. Os 
resíduos químicos, por exemplo, são gerados em maior volume e periculosidade pelas indústrias de grande porte. No entanto, laboratórios de universidades, escolas e centros de pesquisa também geram resíduos (LENARDÃO et al., 2003).

Em laboratórios de análises químicas, os resíduos gerados merecem uma considerável atenção. Isto porque estes apresentam elevada complexidade e diversidade físico-química, o que lhes conferem inconstância e variados níveis de toxidade, dificultando seu gerenciamento. Além disso, os resíduos gerados em unidades laboratoriais são, muitas vezes, manuseados inadequadamente. Alguns resíduos de maior periculosidade são acondicionados no próprio laboratório em áreas inadequadas ou inseguras, e outros com menor periculosidade são descartados diretamente na pia (CARDOSO et al., 2010; HIRATA; MACINI, 2002).

Os poucos registros bibliográficos que tratam de gerenciamento de resíduos sólidos em laboratórios são em universidades e abordam geralmente os seguintes aspectos: (i) segregação ou identificação química qualitativa dos agentes tóxicos presentes nos resíduos; (ii) garantia da correta identificação nominal e acondicionamento; (iii) tratamento dos resíduos; e (iv) respeito à legislação quanto à destinação final ambientalmente adequada (ALBERGUINI et al., 2003; CARDOSO et al., 2010; PENATTI, 2008). Outros trabalhos abordam o gerenciamento de resíduos específicos de alta toxicidade, como é o caso do Cromo VI, e apontam alternativas interessantes de reaproveitamento ou até mesmo reciclagem como reagente químico que serão discutidas adiante (ABREU; TOFOLLI, 2009; FREITAS; MELNIKOV, 2006; GIOVANNINI et al., 2008; MACHADO et al., 2011).

Entretanto, um aspecto quase sempre negligenciado é que eliminar a geração de resíduo é a maneira mais eficaz para a preservação ambiental. A Política Nacional de Resíduos Sólidos, instituída pela Lei no 12.305 (BRASIL, 2010), tem como um de seus objetivos não geração, redução, reutilização, reciclagem e tratamento dos resíduos sólidos, bem como disposição final ambientalmente adequada dos rejeitos. Ou seja, seguindo essa ordenação, um gerenciamento de resíduo eficaz e ambientalmente responsável deve estar sempre buscando, em primeiro lugar, possibilidades de eliminação da geração de resíduo. Em último caso onde a reciclagem é inviável e não houver possibilidade de substituição da metodologia analítica, deverá ser realizado o seu descarte de maneira ambientalmente segura (GOMES et al., 2013; REINHARDT et al., 1996). 
Em complementação à Lei no 12.305 (BRASIL, 2010) há, em nível nacional, uma regulação da emissão de resíduos, responsabilização dos agentes poluidores e promoção de práticas sustentáveis. A Resolução no 357 do CONAMA (Conselho Nacional do Meio Ambiente), de 2005 (BRASIL, 2005), dispõe sobre a classificação dos corpos de água e diretrizes ambientais para o seu enquadramento, bem como estabelece as condições e padrões de lançamento de efluentes e menciona as penalidades aos infratores que são detalhadas em legislações específicas. A Resolução $\mathrm{n}^{\circ}$ 430, de 2011 (BRASIL, 2011), complementa a Resolução n 357 dispondo sobre as condições e padrões de lançamento de efluentes. A norma da ABNT (Associação Brasileira de Normas Técnicas) NBR 10.004, de 2004 (ABNT, 2004), que classifica os resíduos sólidos quanto aos seus riscos ambientais e à saúde pública. Já a nível estadual há, em Goiás, a Instrução Normativa $n^{0}$ 07, de 2011, da SEMARH (Secretaria de Estado de Meio Ambiente dos Recursos Hídricos) (SEMARH, 2011), que regula o gerenciamento e disposição final de resíduos sólidos. Esses instrumentos legais trazem definições e limites importantes para o desenvolvimento deste trabalho.

Uma importante definição é a de "Resíduo sólido", sobre a qual tanto a NBR 10.004, de 2004 (ABNT, 2004), a PNRS (Lei no 12.305, de 2010) (BRASIL, 2010), e a SEMARH 07, de 2011 (SEMARH, 2011), concordam entre si com diferenças insignificantes para este estudo. Segundo a Lei 12.305/2010 (BRASIL, 2010), Art. $3^{\circ}$, XVI:

Resíduos sólidos: material, substância, objeto ou bem descartado resultante de atividades humanas em sociedade, a cuja destinação final se procede, se propõe proceder ou se está obrigado a proceder, nos estados sólido ou semissólido, bem como gases contidos em recipientes e líquidos cujas particularidades tornem inviável o seu lançamento na rede pública de esgotos ou em corpos d'água, ou exijam para isso soluções técnica ou economicamente inviáveis em face da melhor tecnologia disponível.

A Lei 12.305, de 2010 (BRASIL, 2010), responsabiliza o poder público, o setor empresarial e a coletividade pela efetividade das ações voltadas a assegurar a observância da Política Nacional de Resíduos Sólidos. É possível observar que o poder público, pessoa jurídica de direito público ou privado, também pode se enquadrar como gerador de resíduo sólido (Lei n ${ }^{0} 12.305$, de 2010) (BRASIL, 2010). 
Depreende-se ainda do texto que alguns dos resíduos laboratoriais, que estão no estado líquido, se enquadram na definição de resíduos sólidos por não poderem ser descartados em esgotos ou corpos d'água. Assim, é função dos laboratórios de análises químicas zelarem pelo manuseio de produtos químicos bem como pela destinação ou disposição final ambientalmente adequada de seus resíduos sólidos e rejeitos (Lei no 12.305, de 2010) (BRASIL, 2010).

Nesse sentido, esse trabalho se distingue dos demais citados por relatar um gerenciamento de resíduos sólidos de um laboratório de pesquisa agropecuária preocupado inicialmente em reduzir ou eliminar os resíduos gerados. Também procurou demonstrar que esse laboratório avalia as possibilidades de reutilização, reciclagem e tratamento, para só então realizar a disposição final. Foram discutidas as especificidades quanto ao seu gerenciamento dos diversos resíduos tóxicos que são gerados na análise química de solo e planta, e, finalmente, foram relatadas as substituições ou ajustes metodológicos implantados para a racionalização de reagentes e eliminação ou diminuição dos resíduos produzidos. A exposição desse gerenciamento de resíduos sólidos ilustra as definições atuais correlacionadas ao tema e limites tolerados para contaminantes, retirados da legislação vigente.

\section{METODOLOGIA}

O Laboratório de Análise Agroambiental (LAA), do Centro Nacional de Pesquisa de Arroz e Feijão (CNPAF) da Embrapa, localizado no município de Santo Antônio de Goiás (GO), recebeu mais de 15.000 amostras para análises químicas de solo e planta durante o ano, em 2014. Os resultados apresentados nesse trabalho foram obtidos por ações técnicas e gerenciais que vêm sendo executadas no LAA desde 2008 com foco na racionalização do uso de reagentes, redução e tratamento dos resíduos tóxicos gerados.

Esses resíduos são gerados nas análises químicas de solo e tecido vegetal. $\mathrm{Na}$ análise química de solo ou análises de fertilidade são comumente solicitadas as determinações dos seguintes parâmetros: $\mathrm{Ca}, \mathrm{Mg}, \mathrm{K}, \mathrm{Fe}, \mathrm{Zn}, \mathrm{Cu}, \mathrm{Mn}, \mathrm{Al}, \mathrm{PO}_{4}^{\text {; }}, \mathrm{NO}_{3}$; $\mathrm{NH}_{4}^{+}$extraíveis; acidez potencial $(\mathrm{H}+\mathrm{Al}), \mathrm{pH}$ em água, condutividade elétrica e matéria orgânica $(\mathrm{MO})$. Nas análises químicas de tecido vegetal são rotineiramente 
realizadas as seguintes determinações: $\mathrm{Ca}, \mathrm{Mg}, \mathrm{K}, \mathrm{Fe}, \mathrm{Zn}, \mathrm{Cu}, \mathrm{Mn}, \mathrm{P}_{-} \mathrm{PO}_{4}$; totais; e N Kjeldahl (orgânico e amoniacal).

Grande parte destas análises se baseia na passagem dos minerais nutrientes para fase aquosa seguida de determinação. Para solo, esta solubilização se dá pela extração utilizando soluções salinas ou levemente ácidas (PANSU; GAUTHERYOU, 2003). Já para tecido vegetal, são solicitados teores totais, por isso essa solubilização se dá pela digestão ácida da amostra, utilizando como oxidantes ácidos fortes e aquecimento (KARLA, 1998). Em seguida, os minerais do solo ou planta são determinados pelas técnicas de espectroscopia atômica, espectrofotometria, titulometria ou potenciometria.

Dentre os variados métodos utilizados nessas análises, o método WalkleyBlack (DIAZ-ZORITA, 1999; WALKLEY; BLACK, 1934) para determinação da matéria orgânica (MO) do solo merece destaque pelo tipo de resíduo gerado. Nesse pesase $0,5 \mathrm{~g}$ de amostra em erlenmeyer de vidro, adiciona $10,0 \mathrm{~mL}$ de dicromato de potássio $\left(\mathrm{K}_{2} \mathrm{Cr}_{2} \mathrm{O}_{7}\right)$ 0,1667 mol.L-1 e 20,0 mL de ácido sulfúrico P. A. Em seguida agitase a amostra por 1 minuto, deixa a solução em repouso por 30 minutos e adiciona-se $200 \mathrm{~mL}$ de água deionizada e 10,0 mL de ácido fosfórico P. A. Finalmente, titulam-se as amostras com solução contendo íon ferroso $\left(\mathrm{Fe}^{2+}\right) 0,5 \mathrm{~mol} \mathrm{~L}-1 \mathrm{em} \mathrm{pH} 0,3$, gerando ao final cerca de $260 \mathrm{~mL}$ de resíduo sulfocrômico.

Realizou-se uma revisão dos instrumentos legais, que são aplicáveis ao gerenciamento de resíduos sólidos do LAA, já indicada na introdução. Em seguida, detalha-se o gerenciamento de resíduos sólidos praticado pelo LAA desde identificação da toxicidade, acondicionamento, mitigação e destinação ou disposição final ambientalmente adequada. Além disso, detalham-se estudos seguidos de medidas que o LAA vêm adotando desde 2009 para eliminação ou redução da geração de resíduos sólidos e a possibilidade de reciclagem do resíduo contendo cromo.

\section{RESULTADOS E DISCUSSÃO}

\subsection{GERENCIAMENTO DE RESÍDUOS SÓLIDOS NO LAA}

O gerenciamento de resíduo sólido (Lei ${ }^{0}$ 12.305, de 2010) (BRASIL, 2010) do LAA se inicia na identificação dos resíduos, compreensão das suas particularidades 
toxicológicas e classificação segundo NBR 10.004, de 2004 (ABNT, 2004), que é a mesma adotada pela SEMARH 07, de 2011 (SEMARH, 2011).

Na primeira etapa, extração ou digestão ácida, dos procedimentos analíticos para análise de solo e planta já são gerados resíduos sólidos, pois devido ao seu pH estar fora da faixa 5-9 (CONAMA $\mathrm{n}^{\circ} 430$, de 2011) (BRASIL, 2011) fica inviabilizado o lançamento como efluente sem prévia neutralização. Segundo ABNT 10.004, de 2004 (ABNT, 2004), este resíduo é da classe I (perigosos) e caracterizado quanto à sua corrosividade (código D002) por apresentar $\mathrm{pH}$ inferior a 2. No LAA, a determinação dos metais $\mathrm{Ca}, \mathrm{Mg}, \mathrm{Fe}, \mathrm{Zn}, \mathrm{Cu}$ e $\mathrm{Mn}$ é realizada por espectroscopia de absorção atômica em chama de ar/acetileno. O K é determinado por espectroscopia de emissão atômica em fotômetro de chama (SILVA, 2009). Na utilização destas duas técnicas de determinação de metais também é gerado resíduo classe I D002.

Já para análise do $\mathrm{P}$ como $\mathrm{PO}_{4}$, tanto para solo como para tecido vegetal, é utilizada a espectroscopia molecular na região do visível. A diferença consiste na utilização do método do azul de molibdênio (HOLMAN, 1943; SILVA, 2009) para as amostras de solo, que apresentam teores inferiores, já que este método é mais sensivel quando comparado ao método do amarelo de metavanadato (HOLMAN, 1943; KISTON; MELLON, 1944), utilizado para amostras de tecido vegetal. O vanádio (V), presente no ânion metavanadato $\left(\mathrm{VO}_{3}^{-}\right)$, é tóxico, pois tem efeito mutagênico em células germinativas e pode provocar problemas respiratórios (CETESB, 2012). Apesar disso, o $\mathrm{V}$ como $\mathrm{VO}_{3}^{-}$não é regulado pela CONAMA no 430, de 2011 (BRASIL, 2011), para efluentes, nem citado como agente perigoso pela NBR 10.004, de 2004 (ABNT, 2004).

$\mathrm{NO}_{3}^{-}$e $\mathrm{NH}_{4}^{+}$são determinados através da análise por injeção de fluxo e o princípio também é por espectroscopia molecular. Para $\mathrm{NO}_{3}^{-}$utiliza-se a reação de Griess através da substância orgânica sulfanilamida (GRIESS, 1879; SHINN, 1941) e para $\mathrm{NH}_{4}^{+}$, o método conhecido como azul de indofenol (BERTHELOT, 1859; VERDOUW et al., 1978). Este último utiliza como catalisador nitroprussiato de sódio, que em sua constituição apresenta cianeto ( $\mathrm{CN})$. Esse ânion em pH básico encontrase complexado e aquoso, sem risco ao laboratorista. O cianeto, que é desprendido deste reagente como gás em meio ácido, é um composto de alta toxicidade para organismos vivos, podendo trazer grandes complicações ao sistema circulatório, 
alterações cardiovasculares, dispneia, inconsciência e efeitos tóxicos para o fígado e os rins. A dose letal do cianeto é muito pequena, entre 0,5 e $3,5 \mathrm{mg} \cdot \mathrm{kg}^{-1}$ (CONCISE INTERNATIONAL CHEMICAL ADDESMENTE, 2004; MERCK, 2012). Na NBR 10.004, de 2004, o CN- é listado como substância agudamente tóxica, anexo D, código P030, ou seja, que pode levar a sérios danos ou até mesmo à morte por uma única ingestão elevada. Assim, este resíduo foi classificado como classe 1 quanto à sua toxicidade e é acondicionado e tratado no LAA isoladamente.

$\mathrm{Na}$ análise de $\mathrm{MO}$ em solo, através do método Walkley-Black gera-se resíduo ácido contendo cromo que ocorre naturalmente no ambiente em seu estado trivalente $\left(\mathrm{Cr}^{3+}\right)$ e é até considerado essencial aos seres vivos. No entanto, sua forma hexavalente $\left(\mathrm{Cr}^{6+}\right)$, que pode penetrar na pele, é extremamente tóxica aos seres vivos, inclusive ao homem, pois pode causar ulcerações, irritação, inflamação e está associado ao risco de câncer (COHEN et al., 1993; NRIAGU; NIEBOER, 1988). Resíduo classe 1 caracterizado pela sua toxicidade.

Por fim, na determinação de nitrogênio (N) total pelo método convencional de destilação Kjeldahl (AOAC, 1990; KJELDAHL, 1883), utiliza-se sulfato de cobre penta-hidratado como catalisador na digestão ácida sulfúrica. O cobre $(\mathrm{Cu})$ é tóxico em altas concentrações, podendo causar vômito, letargia, anemia hemolítica aguda, dano renal e hepático, e até levar à morte (CETESB, 2012). Este elemento é prejudicial também para a vida aquática, apesar de ser considerado essencial em concentrações baixas, quando em alta concentração interfere no metabolismo celular dos seres aquáticos, podendo comprometer também funções básicas como reprodução e respiração (MAZON et al., 2002; PELGROM, 1994). Devido ao pH superior a 12, este resíduo é da classe I e caracterizado pela sua reatividade como D002, contudo após precipitado (tratamento adotado pelo LAA) este passa a ser da classe II (não inerte) B pois apresenta por teste de solubilização, concentração de Cu superior a 2,0 mg.L.-1. Já na determinação de nitrogênio por espectrofotometria, é necessária a substituição do cobre por selênio (WILLIS, 1996). Este também é tóxico e pode causar fadiga, irritabilidade e danos neurológicos. Já no ambiente aquático, através da acumulação em detritos, pode causar sérios danos à biota e mortalidade de peixes (HAMILTON, 2004; OLIVAS et al., 1994).

Além da identificação, classificação e consciência dos usuários sobre a toxicidade dos resíduos sólidos gerados pelo LAA, o gerenciamento de resíduos sólidos 
se estende ao: (i) tratamento dos mesmos e à (ii) destinação final ambientalmente adequada. O Quadro 1 descreve estes outros 2 passos do gerenciamento pelo LAA; caracteriza os resíduos sólidos pelo $\mathrm{pH}$ e constituinte tóxico; e identifica a análise de origem de cada um. Em linhas gerais, o tratamento dos resíduos consiste na redução da toxicidade (como a redução do $\mathrm{Cr}^{6+}$ a $\mathrm{Cr}^{3+}$, ou oxidação do $\mathrm{CN}^{-}$a $\mathrm{CO}_{2}$ ) e do volume através da precipitação, assim como objetiva a Lei $\mathrm{n}^{\mathrm{O}} 12.305$, de 2010 (BRASIL, 2010), $\operatorname{Art}^{\circ}$ 7, inciso V. A quantidade de reagente necessário para o tratamento dos resíduos foi estimada pela estequiometria das reações envolvidas, Quadro 2, sempre adicionando um excesso mínimo de 10\%. As versões comerciais das substâncias utilizadas são preferidas por baratear o tratamento. O LAA não gera resíduos orgânicos regulados pela legislação vigente para efluentes ou de toxicidade relevante. Além disso, a carga orgânica que sai do laboratório passa por tratamento biológico em sistema anaeróbico na Estação de Tratamento de Efluente da Embrapa Arroz e Feijão. Por fim, mesmo algumas substâncias orgânicas danosas ao meio ambiente são passíveis de biodecomposição, a exemplo, Souza e Rosado (2009) discutem a utilização de fungos em biodegradação de efluentes têxteis.

Quadro 1. Descrição dos resíduos sólidos gerados pelo Laboratório de Análise Agroambiental com seus respectivos tratamentos e destinações finais

(continua)

\begin{tabular}{|l|l|l|l|l|}
\hline $\begin{array}{l}\text { Parâmetro(s) } \\
\text { analisado(s) }\end{array}$ & $\mathrm{pH}$ & $\begin{array}{l}\text { Concentração } \\
\text { do constituinte } \\
\text { tóxico }\end{array}$ & $\begin{array}{l}\text { Tratamento ou mitigação } \\
\text { adotado no LAA }\end{array}$ & $\begin{array}{l}\text { Destinação final } \\
\text { ambientalmente adequada }\end{array}$ \\
\hline \multicolumn{5}{|c|}{ Provenientes da análise química de solo } \\
\hline $\mathrm{Ca}, \mathrm{Mg}, \mathrm{K}$ & 0,4 & n.a & Neutralização & $\begin{array}{l}\text { Se } 5<\mathrm{pH}<9 \text {, então lança- } \\
\text { se como efluente }\end{array}$ \\
\hline $\mathrm{P}$ & $<0$ & n.a & Neutralização & $\begin{array}{l}\text { Se } 5<\mathrm{pH}<9 \text {, então lança- } \\
\text { se como efluente }\end{array}$ \\
\hline $\begin{array}{l}\mathrm{Cu}, \mathrm{Zn}, \mathrm{Fe}, \\
\mathrm{Mn}\end{array}$ & 1,1 & n.a & Neutralização & $\begin{array}{l}\text { Se } 5<\mathrm{pH}<9 \text {, então lança- } \\
\text { se como efluente }\end{array}$ \\
\hline $\mathrm{H}+\mathrm{Al}, \mathrm{Al}$ & 8,0 & n.a & n.a & Lançamento como efluente \\
\hline
\end{tabular}


(continua)

\begin{tabular}{|c|c|c|c|c|}
\hline $\mathrm{NO}_{3} \cdot$ & 0,5 & n.a & Neutralização & $\begin{array}{l}\text { Se } 5<\text { pH }<9 \text {, então } \\
\text { descarta-se o material como } \\
\text { efluente }\end{array}$ \\
\hline $\mathrm{NH}_{4}^{+}$ & 12,0 & $\begin{array}{l}{\left[\mathrm{CN}^{-}\right] \sim 12} \\
\mathrm{mg} \cdot \mathrm{L}^{-1}, \mathrm{como} \\
{\left[\mathrm{Fe}(\mathrm{CN})_{5} \mathrm{NO}^{2 \cdot}\right.}\end{array}$ & $\begin{array}{l}\text { Oxidação completa do } \\
\text { CN` com hipoclorito } \\
\text { comercial, seguido de } \\
\text { neutralização }\end{array}$ & $\begin{array}{l}\text { Após o resultado negativo } \\
\text { para teste de CN residual, e } \\
5<\text { pH }<9 \text {, então lança-se } \\
\text { como efluente }\end{array}$ \\
\hline MO & $<0$ & $\begin{array}{l}{\left[\mathrm{Cr}^{3+, 6+}\right] \sim} \\
5800 \mathrm{mg} \cdot \mathrm{L}^{-1}\end{array}$ & $\begin{array}{l}\text { Redução do } \mathrm{Cr}^{+6} \mathrm{a} \mathrm{Cr}^{3+} \\
\text { com álcool comercial } \\
\text { ou esponja de aço, } \\
\text { elevação do pH até } 8 \\
\text { para precipitação do } \\
\mathrm{Cr}(\mathrm{OH})_{3} . \text { Separação } \\
\text { do sobrenadante e do } \\
\text { precipitado verde por } \\
\text { sifonação após decantação } \\
\text { ou por filtração }\end{array}$ & $\begin{array}{l}\text { Se o sobrenadante contiver } \\
{\left[\mathrm{Cr}^{3+}\right]<1,0 \text { mg. } \mathrm{L}^{-1} \text { e }\left[\mathrm{Cr}^{6+}\right]} \\
<0,1 \mathrm{mg} . \mathrm{L}^{-1} \text {, então lança-o } \\
\text { como efluente. O precipitado } \\
\text { contendo } \mathrm{Cr}(\mathrm{OH})_{3} \\
\text { sofre disposição final } \\
\text { ambientalmente adequada } \\
\text { em aterro industrial ou tipo I }\end{array}$ \\
\hline & & & $\begin{array}{l}\text { Provenientes da análise } \\
\text { química de tecido vegetal }\end{array}$ & \\
\hline $\mathrm{Ca}, \mathrm{Mg}, \mathrm{K}$ & 0,1 & n.a & Neutralização & $\begin{array}{l}\text { Se } 5<\mathrm{pH}<9 \text {, então lança- } \\
\text { se como efluente }\end{array}$ \\
\hline$P$ & $<0$ & $\begin{array}{l}{\left[\mathrm{V}^{5+}\right] \sim 11} \\
\mathrm{mg} \cdot \mathrm{L}^{-1} \text { como } \\
\mathrm{VO}_{3}^{-}\end{array}$ & $\begin{array}{l}\text { Elevação do pH para } \\
\text { 7-8 para precipitação } \\
\text { do V como } \mathrm{V}(\mathrm{OH})_{5} \text {. } \\
\text { Filtração para retenção do } \\
\text { precipitado }\end{array}$ & $\begin{array}{l}\text { A concentração de V não } \\
\text { é regulada para efluente. } \\
\text { O sobrenadante é lançado } \\
\text { como efluente e o } \\
\text { precipitado retido no papel } \\
\text { de filtro sofre disposição final } \\
\text { ambientalmente adequada } \\
\text { em aterro industrial ou tipo I }\end{array}$ \\
\hline $\begin{array}{l}\mathrm{Cu}, \mathrm{Zn}, \mathrm{Fe} \\
\mathrm{Mn}\end{array}$ & $<0$ & n.a & Neutralização & $\begin{array}{l}\text { Se } 5<\mathrm{pH}<9 \text {, então lança- } \\
\text { se como efluente }\end{array}$ \\
\hline N-Kjeldahl & 14,0 & $\begin{array}{l}{\left[\mathrm{Cu}^{2+}\right] \sim 1800} \\
\mathrm{mg} . \mathrm{L}^{-1} \text { como } \\
\mathrm{CuO}\end{array}$ & $\begin{array}{l}\text { Após decantação do } \\
\mathrm{Cu}(\mathrm{OH})_{2} \text { (precipitado } \\
\text { escuro), separação por } \\
\text { sifonação e neutralização } \\
\text { do sobrenadante }\end{array}$ & $\begin{array}{l}\text { Se o sobrenadante contiver } \\
{[\mathrm{Cu}]<1,0 \text { mg. } \mathrm{L}^{-1} \text {, então }} \\
\text { lança-o como efluente. } \\
\mathrm{O} \text { precipitado contendo } \\
\mathrm{Cu}(\mathrm{OH})_{2} \text { sofre disposição } \\
\text { final ambientalmente } \\
\text { adequada em aterro } \\
\text { industrial ou tipo I }\end{array}$ \\
\hline
\end{tabular}


(conclusão)

\begin{tabular}{|c|c|c|c|c|}
\hline N-Berthelot & $<0$ & $\begin{array}{l}{[\mathrm{Se}] \sim 700} \\
\mathrm{mg} . \mathrm{L}^{-1}\end{array}$ & $\begin{array}{l}\text { Redução do Se por } \\
\mathrm{Na}_{2} \mathrm{~S}_{2} \mathrm{O}_{5} \text {, neutralização que } \\
\text { provoca a precipitação } \\
\text { do Se como } \mathrm{Se}_{8} \text {, sólido } \\
\text { avermelhado. Separação } \\
\text { do sobrenadante por } \\
\text { sifonação }\end{array}$ & $\begin{array}{l}\text { Se o sobrenadante contiver } \\
{\left[\text { Se] }<0,3 \text { mg. } \mathrm{L}^{-1} \text {, então }\right.} \\
\text { lança-o como efluente. } \\
\text { O precipitado contendo } \\
\mathrm{Se}_{8} \text { sofre disposição final } \\
\text { ambientalmente adequada } \\
\text { em aterro industrial, ou } \\
\text { tipo I }\end{array}$ \\
\hline
\end{tabular}
inorgânicos foram retirados da Resolução CONAMA n ${ }^{\circ} 430$ de 2011.

Quadro 2. Reações químicas nos tratamentos dos constituintes tóxicos dos resíduos sólidos gerados pelo Laboratório de Análise Agroambiental

\begin{tabular}{|c|c|c|}
\hline \multirow{2}{*}{$\begin{array}{l}\text { Constituinte } \\
\text { tóxico }\end{array}$} & \multicolumn{2}{|c|}{$\begin{array}{l}\text { Tratamento ou mitigação dos constituintes tóxicos presentes nos resíduos das } \\
\text { análises agroambientais }\end{array}$} \\
\hline & Etapa & Reação \\
\hline $\mathrm{CN}^{-}$ & Oxidação & $\begin{array}{l}\mathrm{NaCN}_{(a q)}+\mathrm{NaClO}_{(a q)} \rightarrow \mathrm{NaCNO}_{(a q)}+\mathrm{NaCl}_{(a q)}(\mathrm{pH} 11-13) \\
2 \mathrm{NaClO}_{[a q]}+3 \mathrm{NaClO}_{[\mathrm{aq}]}+\mathrm{H}_{2} \mathrm{O} \rightarrow 2 \mathrm{CO}_{\mho_{g]}}+\mathrm{N}_{[([\mathrm{g})}+3 \mathrm{NaCl}_{[\mathrm{g}]}+\mathrm{NaOH}_{[a q]}(\mathrm{pH} 6,0-8,0)\end{array}$ \\
\hline \multirow{2}{*}{$\mathrm{Cr}^{+3,+6}$} & Redução & $2 \mathrm{Cr}_{2} \mathrm{O}_{[(\mathrm{aq}]}^{-2}+3 \mathrm{C}_{2} \mathrm{H}_{5} \mathrm{OH} \mathrm{H}_{(\mathrm{Q})}+16 \mathrm{H}_{[\mathrm{aqq}]}^{+}+4 \mathrm{Cr}_{[\mathrm{aq}]}^{+3}+3 \mathrm{CH}_{3} \mathrm{OOOH}_{[\mathrm{QQq})}+11 \mathrm{H}_{2} \mathrm{O}(\mathrm{pH} \sim 0)$ \\
\hline & Precipitação & $\mathrm{Cr}_{(a q)}^{3+}+30 \mathrm{H}_{(a q)}^{-} \rightarrow \mathrm{Cr}(\mathrm{OH})_{3(s)}\left(\mathrm{pH}_{7,0-9,0)}\right.$ \\
\hline $\mathrm{V}^{+5}$ & Precipitação & $\mathrm{V}_{(a a)}^{5+}+5 \mathrm{OH}_{(\mathrm{aq})}^{-} \rightarrow \mathrm{V}_{(\mathrm{OH})_{5(s)}}(\mathrm{pH} 7,0-8,0)$ \\
\hline $\mathrm{Cu}^{+2}$ & Precipitação & $\begin{array}{l}\mathrm{CuSO}_{4(\mathrm{aq})}+2 \mathrm{NaOH}_{(\mathrm{aq})} \rightarrow \mathrm{Cu}(\mathrm{OH})_{(\mathrm{s})}+\mathrm{Na}_{2} \mathrm{SO}_{4}(\mathrm{aq})(\mathrm{pH} \\
\sim 14)\end{array}$ \\
\hline $\mathrm{Se}^{+4}$ & $\begin{array}{l}\text { Redução e } \\
\text { precipitação }\end{array}$ & $8 \mathrm{SeO}_{3(\mathrm{aq}]}^{2-}+8 \mathrm{Na}_{2} \mathrm{~S}_{2} \mathrm{O}_{5[\mathrm{aq}]} \rightarrow \mathrm{Se}_{\mathrm{B(s]}]}+8 \mathrm{Na}_{2} \mathrm{SO}_{4(\mathrm{aq})}+8 \mathrm{SO}_{4(\mathrm{aq})}^{2-}(\mathrm{pH} \sim 0)$ \\
\hline
\end{tabular}

Os rejeitos (Lei $\mathrm{n}^{\mathrm{O}}$ 12.305, de 2010) (BRASIL, 2010), segregados por precipitação, recebem etiqueta com indicação do composto tóxico, classificação segundo NBR 10.004, de 2004 (ABNT, 2004), quantidade e procedência. Em seguida, são encaminhados para um recinto, Figura 1, independente do laboratório e construído segundo exigências da NBR 12.235, de 1992 (ABNT, 1992), para armazenagem de resíduos sólidos classe 1 (perigosos). 

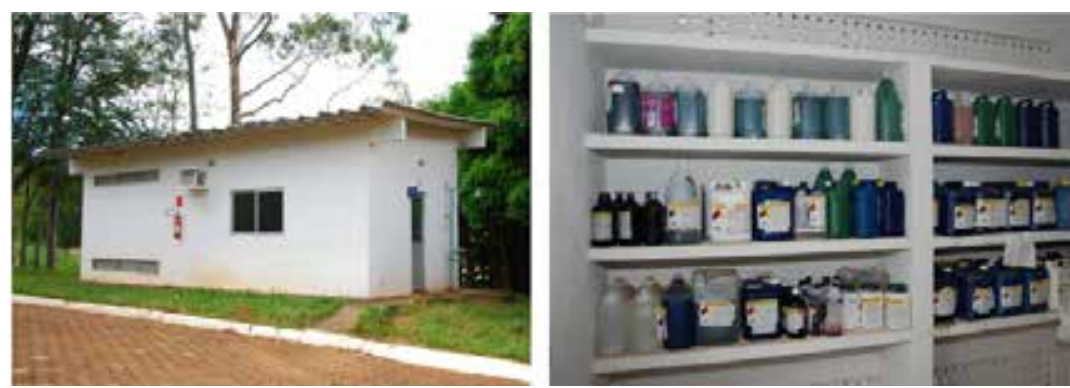

Figura 1. Recinto para armazenagem de resíduos sólidos classe 1 (perigosos). À esquerda vista externa e à direita vista interna

A Resolução CONAMA n ${ }^{\circ}$ 430, de 2011 (BRASIL, 2011), contempla uma gama muito restrita de substâncias e elementos tóxicos, sendo necessária a verificação da periculosidade pela NBR 10.004, de 2004 (ABNT, 2004), que é mais abrangente. Mesmo assim, quando a equipe técnica do LAA tem conhecimento da toxicidade de um resíduo que não está contemplado nos instrumentos legais vigentes, realizase o tratamento ou mitigação do mesmo, em consonância com o princípio da razoabilidade e proporcionalidade, previsto no Art. 6, inciso XI, da Lei ${ }^{0} 12.305$, de 2010 (BRASIL, 2010).

\subsection{MINIMIZAÇÃO DA GERAÇÃO DE RESÍDUOS SÓLIDOS E REJEITOS NO LAA}

Nos últimos 20 anos vem crescendo a atenção aos resíduos químicos, isso se deve à preocupação com as reservas ambientais e com a prevenção aos acidentes ambientais de proporções desastrosas. Isto induziu o Estado a confeccionar legislação mais rígida aos crimes ambientais e mais restritiva quanto aos limites de tolerância para os rejeitos tóxicos da produção. Assim, a indústria e outros geradores se viram obrigados a otimizar processos e buscar alternativas limpas que eliminem ou minimizem a geração de resíduos sólidos. Esta tendência de inovação limpa que também vem sendo adotada no LAA foi denominada de Green Chemistry, ou química verde, e apresenta dentre os seus princípios: (i) prevenção da geração de resíduos; (ii) economia de átomos ou desenvolvimento de processos sintéticos; (iii) desenho de produtos seguros; (iv) química intrinsecamente segura para prevenção 
de acidentes (BAIRD, 1995; LENARDÃO et al., 2003; PRADO, 2003; SILVA et al., 2005).

Os princípios da química verde, mesmo que de maneira não premeditada, foram incorporados na instituição da Política Nacional de Resíduos Sólidos, através da atual Lei no 12.305, de 2010 (BRASIL, 2010), e estão presentes no Título II, Capítulo II "dos princípios e objetivos" e no conceito "responsabilidade compartilhada pelo ciclo de vida dos produtos". Depreende-se desse conceito que é responsabilidade de todas as pessoas jurídicas envolvidas no processo de produção a minimização da geração de resíduos sólidos e rejeitos, e a redução dos impactos ambientais decorrentes destes. A equipe do LAA realiza constantemente revisões bibliográficas, otimizações ou comparações metodológicas para embasarem a gestão laboratorial na tomada de decisões técnicas que reduzam a geração de resíduos sólidos e rejeitos sem perda na qualidade das determinações.

No método original do azul de indofenol (BOLLTER et al., 1961; PATTON; CROUCH, 1977) foi utilizado fenol, que é uma substância orgânica tóxica pelo seu efeito irritante às membranas mucosas, por afetar o sistema nervoso central e apresentar atividade carcinogênica a longo prazo. Verdouw et al. (1978) ajustaram o método para a substituição do fenol por salicilato de sódio, que produz a mesma cor, viabilizando determinação espectrofotométrica do $\mathrm{NH}_{4}^{+}$, e apresenta toxicidade extremamente reduzida relativamente ao primeiro. Com isto, o LAA utiliza o método ajustado.

Até o ano de 2010, a análise mais crítica no LAA quanto à geração de resíduo sólido era a determinação de matéria orgânica (MO) do solo pelo método de Walkley-Black. Gerava-se aproximadamente $260 \mathrm{~mL}$ de resíduo sulfocrômico por amostra. Desta forma, em uma semana típica onde são analisadas 120 amostras, eram gerados em torno de 34 litros de resíduo sólido. Foram realizadas duas adaptações metodológicas: a redução da massa de amostra e a substituição da titulação pela determinação espectrofotométrica de MO, possibilitada pela coloração esverdeada do $\mathrm{Cr}^{3+}$ formado na oxidação do carbono orgânico por $\mathrm{Cr}_{2} \mathrm{O}_{7}$. Com isso, conseguiuse uma redução de consumo de reagentes de $80 \%$ para o ácido sulfúrico P. A. e de $60 \%$ para o $\mathrm{K}_{2} \mathrm{Cr}_{2} \mathrm{O}_{7}$ P. A. O volume final de resíduo foi diminuído para $24,0 \mathrm{~mL}$ por amostra, 91\% menor que o original como é demonstrado na Figura 2. 


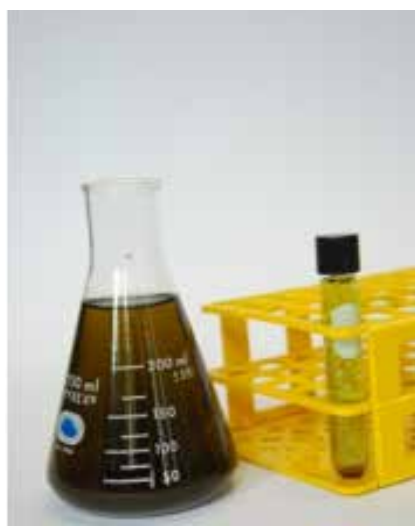

Figura 2. Ilustração da redução de $91 \%$ do volume de resíduo gerado na análise de matéria orgânica do solo. Resíduo do método original no erlenmeyer à esquerda e resíduo do método adaptado no tubo à direita

O LAA avalia ainda a possibilidade de determinação de MO por espectroscopia no infravermelho médio (MIR). Foram construídos modelos multivariados preditores com um conjunto de 1.117 amostras de solo com características diversificadas oriundas de todas as regiões brasileiras. Os resultados publicados recentemente da predição de MO por MIR têm potencial para substituir a metodologia de referência, Walkley-Black, sem perda significativa da qualidade da análise. Esta substituição acarretaria em uma redução adicional na geração de resíduo sólido de $90 \%$, pois seriam necessárias poucas análises pelo método de referência para verificação periódica da qualidade dos resultados MIR (SOUZA et al., 2012a).

Outra redução na geração de resíduos viabilizada no LAA foi obtida através de um estudo que aplicou planejamento fatorial $2^{2}$ para otimizar a extração de minerais de amostras de tecido vegetal. Os fatores avaliados foram tipo de digestão e massa de amostra, em dois níveis: úmida/seca, e $200 \mathrm{mg} / 500 \mathrm{mg}$, respectivamente. Verificou-se que a digestão úmida e $200 \mathrm{mg}$ de amostra foi a melhor condição para extração dos minerais de uma amostra de capim braquiária, escolhido por ser um tipo de tecido vegetal de elevada resistência à oxidação, que está associado ao alto teor de lignina. Assim, modificou-se a massa de amostra para digestão de 500 para $200 \mathrm{mg}$, permitindo uma redução de 60\% dos volumes gastos de ácido nítrico P. A., ácido perclórico P. A. e, consequentemente, do resíduo sólido gerado (SOUZA et al., 2012b). 
Estão em curso outros estudos de implantações metodológicas no LAA, como: (i) determinação de nitrogênio em solo através da espectroscopia MIR; (ii) adaptação do método de Mebius (MEBIUS, 1960) para escala micro, que se utiliza de aquecimento externo das amostras para auxiliar na oxidação da MO, possibilitando economia de $\mathrm{H}_{2} \mathrm{SO}_{4}$ em relação ao Walkley-Black (WALKLEY; BLACK, 1934); (iii) digestão de tecido vegetal através da utilização de persulfato de sódio para eliminar a utilização dos catalisadores de Cu ou Se na análise de N Kjeldahl (PURCELL; KING, 1996). Para determinação de N Kjeldahl existe a opção de realizá-la por analisador elementar de N, que é uma técnica mais operacional, limpa e barata, tendo como única desvantagem o alto custo de investimento para aquisição do equipamento. Um analisador elementar de $\mathrm{N}$ foi adquirido pelo LAA e em breve será instalado. Atualmente o LAA já dispõe de analisador elementar CHNSO que também permite a determinação de $\mathrm{N}$ total simultaneamente ao $\mathrm{C}, \mathrm{H}, \mathrm{S}$ e $\mathrm{O}$, contudo a análise é mais cara, $\mathrm{R} \$ 12,50$, que pelo método Kjeldahl que custa $\mathrm{R} \$ 7,25$.

\subsection{RECICLAGEM DO CROMO}

Pelos princípios da química verde e do ponto de vista legal, antes de classificar um material como rejeito, deve-se avaliar as possibilidades de tratamento e recuperação do composto tóxico. Inclusive a reciclagem é uma das formas de destinação final ambientalmente adequada, desde que seja economicamente viável. O LAA gera pequena quantidade de variados resíduos sólidos, o que dificulta a viabilidade da reciclagem. $\mathrm{O}$ único resíduo sólido que é produzido em quantidade expressiva neste laboratório, e que pela literatura tem possibilidade de reciclagem, é o sulfocrômico oriundo da análise de matéria orgânica (MO).

No Quadro 1 é demonstrado o tratamento deste resíduo até a obtenção de um precipitado verde, $\mathrm{Cr}(\mathrm{OH})_{3}$. Este sólido rotineiramente é considerado rejeito e sofre disposição final ambientalmente adequada em aterro industrial. Um estudo foi realizado no LAA para verificar a possibilidade de reciclagem deste resíduo sólido.

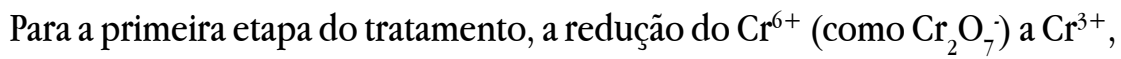
foram encontrados na literatura três diferentes agentes redutores: metabissulfito de sódio, lã de aço, e álcool etílico (HIRATA; MACINI, 2002; MACHADO et al., 2011). 
Decidiu-se utilizar o álcool etílico comercial devido a seu baixo custo e por não contaminar o resíduo com óxido de ferro como acontece com a lã de aço. Essa etapa se trata da mitigação do constituinte tóxico, pois a forma trivalente do cromo é menos danosa que sua forma hexavalente ao meio ambiente e à saúde humana.

O sólido verde final $\left(\mathrm{Cr}(\mathrm{OH})_{3}\right)$ foi lavado 5 vezes com água e em cada etapa aguardou-se a decantação por 24 horas para a devida separação de fases. Nas sucessivas lavagens, objetivou-se a solubilização do $\mathrm{Na}_{2} \mathrm{SO}_{4}$, oriundo da neutralização do $\mathrm{H}_{2} \mathrm{SO}_{4}$ com $\mathrm{NaOH}$, bem como outros sais não tóxicos solúveis presentes. Obtevese apenas $100 \mathrm{~g}$ de resíduo, de coloração verde intensa, para cada $1 \mathrm{~L}$ de resíduo tratado e lavado, ou seja redução de $90 \%$ (Figura 3). Os sobrenadantes das lavagens tiveram as concentrações de $\mathrm{Cr}^{3+}$ monitoradas por espectroscopia de absorção atômica em chama, antes do lançamento como efluente e apresentaram valores abaixo do máximo permitido de 1,0 mg..-1 ${ }^{-1}$ pela Resolução CONAMA n ${ }^{0}$ 430, de 2011 (BRASIL, 2011).

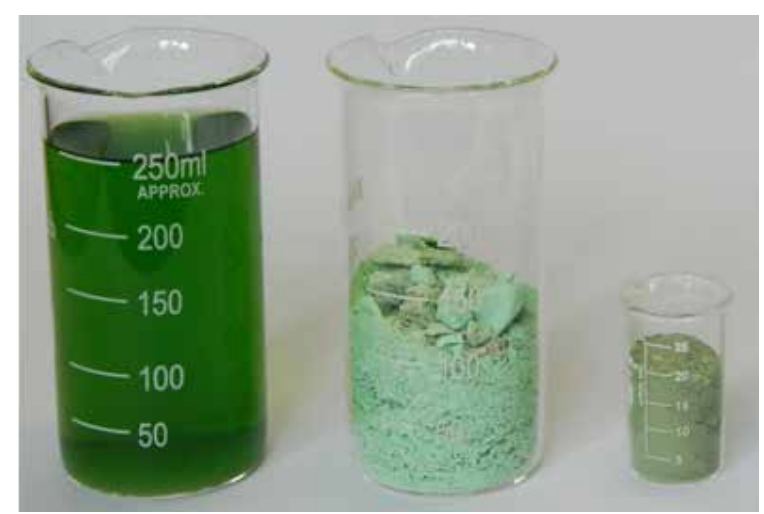

Figura 3. Resíduo da análise de MO após redução do cromo VI a cromo III no béquer à esquerda; precipitado do resíduo contendo cromo III no béquer central; e precipitado de cromo III após 5 lavagens sucessivas com água no béquer à direita

Após as lavagens, esse resíduo sólido do LAA foi digerido para determinação dos teores totais de 5 compostos que precipitam e apresentou a seguinte constituição (VOGEL, 1985): $\mathrm{Cr}(\mathrm{OH})_{3}$ (33,44\% contra 2,97\% no resíduo não lavado), $\mathrm{Fe}(\mathrm{OH})_{3}$ $(8,90 \%), \mathrm{Mn}(\mathrm{OH})_{3}(0,02 \%), \mathrm{Mg}(\mathrm{OH})_{3}(0,04 \%), \mathrm{e} \mathrm{CaCO}_{3}(0,36 \%)$, totalizando $42,77 \%$. Além desses, ainda foi detectada a presença de $\mathrm{NaSO}_{4}$. 
$\mathrm{Na}$ última década foram publicados vários estudos sobre o tratamento $\mathrm{e}$ possíveis reutilizações de resíduo sólido contendo $\mathrm{Cr}$, oriundo de indústrias de curtume e laboratórios (ABREU; TOFOLLI, 2009; FREITAS; MELNIKOV, 2006; GIOVANNINI et al., 2008; MACHADO et al., 2011).

Machado et al. (2011) propuseram a reciclagem do cromo para utilização no próprio laboratório sem perda de qualidade da determinação envolvida. Após a obtenção do $\mathrm{Cr}(\mathrm{OH})_{3}$, elevaram o pH para solubilização do sólido, em seguida adicionaram peróxido de hidrogênio $\left(\mathrm{H}_{2} \mathrm{O}_{2}\right) \mathrm{P}$. A. para oxidação do $\mathrm{Cr}^{3+}$ a cromato $\left(\mathrm{CrO}_{4}^{2}\right)$. Por fim, adicionaram $\mathrm{H}_{2} \mathrm{SO}_{4}$ P. A. para obterem uma solução de $\mathrm{Cr}_{2} \mathrm{O}_{7}^{2}$. Esta, por sua vez, foi padronizada e reutilizada na análise de carbono orgânico oxidável em fertilizantes, própria análise que originou o resíduo inicial. Esta opção foi testada no LAA para análise de MO em solo e se mostrou estatisticamente satisfatória, pois, ao nível de $95 \%$ e 4 graus de liberdade, não foi detectada diferença para as médias do teor de MO para as 2 amostras avaliadas. Contudo, não se mostrou aplicável à rotina, pois o método não é viável do ponto de vista econômico e operacional, já que neste laboratório a mão de obra é limitada em relação ao volume de trabalho anual.

Uma alternativa promissora é a reutilização do óxido de cromo na pigmentação de tintas e produtos cerâmicos, mas na prática é dificultada devido aos altos padróes de qualidade dos insumos destas indústrias e por desconhecerem a constituição exata do resíduo tratado (ABREU; TOFOLLI, 2009). Lucas e Benatti (2008) fizeram uma revisão demonstrando que alternativas correlatas a essa vêm sendo realizadas através da utilização de resíduos da indústria na constituição de artefatos cimentícios e argilosos para construção civil. Já Silva et al. (2010) demonstram que as indústrias muitas vezes não fazem o adequado aproveitamento dos subprodutos como é o caso das agroindústrias sucroalcooleiras do Paraná em relação ao bagaço da cana-de-açúcar.

Para obtenção de teores de $\mathrm{Cr}$ mais próximos dos pigmentos comerciais $\left(\mathrm{Cr}_{2} \mathrm{O}_{3}\right.$ de 80 a 100\%) através de resíduos como do LAA, deverão ser avaliados em estudos futuros: (i) a adição de mais etapas de lavagens de maneira automatizada, (ii) a possibilidade de separação eletromagnética do Fe presente, já que está em

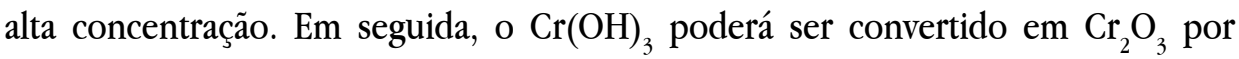
calcinação, para, finalmente, ser caracterizado detalhadamente e testado quanto à sua eficácia como pigmento de pureza elevada. 
O resíduo da análise de $\mathrm{MO}$, depois de tratado, foi reduzido a menos de $10 \%$ da massa inicial. Mesmo ainda não sendo reciclado rotineiramente, isso diminui o custo e espaço necessário para a disposição final ambientalmente adequada em aterro industrial. As etapas de lavagens do resíduo aumentaram de 2,97\% para 33,44\% o teor de $\mathrm{Cr}(\mathrm{OH})_{3}$. Os resultados não são conclusivos, mas entende-se possível, a partir deste material, alcançar teores de $\mathrm{Cr}_{2} \mathrm{O}_{3}$ e características comparáveis a pigmentos comerciais, que seria uma alternativa para reutilização do mesmo sem a necessidade de disposição final em aterro industrial.

\section{CONSIDERAÇÕES FINAIS}

Os resultados demonstram que várias alternativas devem ser consideradas para um gerenciamento eficaz de resíduos sólidos. Essas alternativas são aplicáveis a quaisquer laboratórios, independentemente dos tipos de ensaios realizados. A racionalização do consumo de reagentes pode ser possível com modificações metodológicas que não prejudiquem os resultados, diminuindo a geração de resíduos, a exemplo que aconteceu no LAA na análise de tecido vegetal e de matéria orgânica do solo. Outra alternativa é a substituição de reagentes tóxicos por outros menos tóxicos que possam conduzir a um resultado equivalente como a substituição do fenol por salicilato de sódio na análise espectrofotométrica de amônio extraível do solo. Por fim, um gerenciamento de resíduos sólidos de um laboratório deve buscar o tratamento ou mitigação dos constituintes tóxicos de seus resíduos que não puderam ser totalmente eliminados. A oxidação do cianeto a gás carbônico e redução do cromo hexavalente para trivalente são exemplos de tratamento e mitigação, respectivamente, adotados pelo LAA. Os laboratórios devem preferir substâncias químicas que têm versões comerciais, ou seja, de menor pureza, frente às substâncias de alta pureza, reagentes de grau analítico, para o tratamento de seus resíduos sólidos, pois se diminui drasticamente os custos.

O Laboratório de Análise Agroambiental da Embrapa Arroz e Feijão vem se destacando quanto à responsabilidade ambiental por estar reduzindo consideravelmente a geração de resíduo sólido, realizando seu tratamento e avaliando 
experimentalmente possibilidades de sua reutilização e sua reciclagem. Isso significa realizar seu gerenciamento de resíduos sólidos em acordo com a Política Nacional de Resíduos Sólidos (Lei n ${ }^{0}$ 12.305, de 2010) e outras ferramentas legais aplicáveis. A principal dificuldade no tratamento dos resíduos sólidos neste laboratório tem sido a baixa operacionalidade dos procedimentos associada à escassez de mão de obra. Desta forma, existe a necessidade de investimento em automação do tratamento de resíduos, como dosagens de reagentes por bombas peristálticas e controle das concentrações através de eletrodos de processo.

\section{REFERÊNCIAS}

ABNT. ASSOCIAÇÃO BRASILEIRA DE NORMAS TÉCNICAS. NBR 10004: Classificação de Resíduos. Rio de Janeiro: ABNT, 2004.

ABNT. ASSOCIAÇÃO BRASILEIRA DE NORMAS TÉCNICAS. NBR 12235: Armazenamento de resíduos sólidos perigosos. Rio de Janeiro: ABNT, 1992.

ABREU, M. A.; TOFFOLI, S. M. Characterization of a chromium-rich tannery waste and its potential use in ceramics. Ceramics International, v. 35, n. 6, p. 2225-2234, 2009.

ALBERGUINI, L. B. A.; SILVA, L. C. 1.; REZENDE, M. O. O. Laboratório de resíduos químicos do campus USP-São Carlos: resultados da experiência pioneira em gestão e gerenciamento de resíduos químicos em um campus universitário. Quim. Nova, v. 26, n. 2, p. 291-295, 2003.

ASSOCIATION OF OFFICIAL ANALYTICAL CHEMISTS (AOAC). Official Methods of Analysis. $15^{\mathrm{a}}$ ed. Arlington, 1990.

BAIRD, C.; CANN, M. Environmental chemistry. Macmillan, 2005.

BERTHELOT, M. P. E. Violet d'aniline. Report Chimie Applications, v. 1, p. 282$844,1859$. 
BRASIL. CONAMA - Conselho Nacional do Meio Ambiente. Resolução CONAMA n ${ }^{\circ}$ 357, de 17 de março de 2005. Dispõe sobre a classificação dos corpos de água e diretrizes ambientais para o seu enquadramento, bem como estabelece as condições e padrões de lançamento de efluentes. Diário Oficial [da] República Federativa do Brasil, Poder Executivo, Brasília, DF, 18 mar. 2005.

BRASIL. CONAMA - Conselho Nacional do Meio Ambiente. Resolução no 430 de 13 de maio de 2011. Dispõe sobre as condições e padrões de lançamento de efluentes, complementa e altera a Resolução $n^{0}$ 357, de 17 de março de 2005, do Conselho Nacional do Meio Ambiente - CONAMA. Diário Oficial [da] República Federativa do Brasil, Poder Executivo, Brasília, DF, 13 maio 2011.

BRASIL. Lei $\mathrm{n}^{\circ} 12.305$ - Institui a Política Nacional de Resíduos Sólidos e dá outras providências. Diário Oficial [da] União. Brasília, DF, 02 de agosto de 2010.

CARDOSO, R. S. et al. Gerenciamento de resíduos químicos gerados nos laboratórios do Centro de Tecnologia da Universidade Federal da Paraíba - CT/UFPB. In: ENCONTRO DE EXTENSÃO, 12, 2010, João Pessoa. Anais... João Pessoa: UFPBPRAC, 2010.

COHEN, M. D. et al. Mechanisms of chromium carcinogenicity and toxicity. CRC Critical Reviews in Toxicology, v. 23, n. 3, p. 255-281, 1993.

COMPANHIA DE TECNOLOGIA DE SANEAMENTO AMBIENTAL (CETESB). Ficha de Informação Toxicológica do Vanádio metálico. 2012. Disponível em: <www. cetesb.sp.gov.br/userfiles/file/laboratorios/fit/vanadio.pdf $>$. Acesso em: 17 maio 2015.

COMPANHIA DE TECNOLOGIA DE SANEAMENTO AMBIENTAL (CETESB). Ficha de informação toxicológica do cobre. 2012. Disponível em: <www.cetesb.sp.gov.br/ userfiles/file/laboratorios/fit/cobre.pdf > . Acesso em: 17 maio 2015.

CONCISE INTERNATIONAL CHEMICAL ASSESMENTE. Document 61; Hydrogen cyanide and cyanides? Human health aspect. Geneva, 2004. Disponível em: $<$ www.inchem.org/documents/cicads/cicads/cicad61.htm >. Acesso em: 17 maio 2015. 
DÍAZ-ZORITA, M. Soil organic carbon recovery by the Walkley-Black method in a typic hapludoll. Communications in Soil Science \& Plant Analysis, v. 30, n. 5-6, p. $739-745,1999$.

ESPÍNDOLA, E. L. G. et al. Ecotoxicologia: perspectivas para o século XXI. São Paulo: RIMA, 2000. 564p.

FREITAS, T. C. M.; MELNIKOV, P. O uso e os impactos da reciclagem de cromo em indústrias de curtume em Mato Grosso do Sul, Brasil. Engenharia Sanitária e Ambiental, v. 11, n. 4, p. 305-310, 2006.

GIOVANNINI, J. G. et al. Avaliação das técnicas de precipitação química e encapsulamento no tratamento e destinação conjunta de resíduos líquidos contendo cromo e vidrarias de laboratório. Química Nova, v. 31, n. 3, p. 676-679, 2008.

GOMES, M. G. et al. Tratamento, Recuperação e Reaproveitamento de Resíduos Químicos Gerados em Laboratórios de Ensino da UFC. Revista Universo \& Extensão, v. 1, n. 1, p. 61-72, 2013.

GRIESS, P. B. D. Bemerkungen zu der Abhandlung der HH: Weseley und Benedikt " $U$ " ber eibige Azoverbindungen. Berichte der Deutschen Chemischen Gesellschaft, v. 12 , p. $426-428,1879$.

HAMILTON, S. J. Review of selenium toxicity in the aquatic food chain. Science of the Total Environment, v. 326, p. 1-31, 2004.

HIRATA, M. H.; MACINI FILHO, J. Manual de Biossegurança. Barueri: Manole, 2002. 496p.

HOLMAN, W. I. M. A new technique for the determination of phosphorus by the molybdenum blue method. Biochem. Journal, v. 37, n. 2, p. 256-259, 1943.

KALRA, Y. P. Handbook of Reference Methods for Plant Analysis. New York: CRC, 1998. 300p.

KITSON, R. E.; MELLON, M. G. Colorimetric determination of phosphorus as molybdivannadophosphoric acid. Industrial \& Engineering Chemistry Research, v. $16,379-383,1944$. 
KJELDAHL, J. A new method for the estimation of nitrogen in organic compounds. Zeitschrift fur Analytische Chemie Fresenius, v. 22, p. 366, 1883.

LENARDÃO, E. J. et al. Green Chemistry - Os 12 Princípios da Química Verde e sua Inserção nas atividades de ensino e pesquisa. Química Nova, v. 26, n. 1, p. 123-129, 2003.

LUCAS, D.; BENATTI, C. T. Utilização de resíduos industriais para a produção de artefatos cimentícios e argilosos empregados na construção civil. Revista em Agronegócio e Meio Ambiente, v. 1, n. 3, p. 405-418, 2008.

MACÊDO, J. A. B. Introdução a química ambiental. Juiz de Fora: CRQ, 2002. 487p.

MACHADO, J. M. C. et al. Reciclagem do crômio de resíduos químicos provenientes da determinação de carbono oxidável em fertilizantes orgânicos. Química Nova, v. 34, n. 1, p. 131-134, 2011.

MAZON, A. F. et al. Hematological and physiological changes induced by short-term exposure to copper in the freshwater fish, Prochilodus scrofa. Brazilian Journal of Biology, v. 62, n. 4A, p. 621-631, 2002.

MEBIUS, L. J. A rapid method for determination of Organic Carbon in Soil. Analytica Chimica Acta, v. 22, p. 120-124, 1960.

MERCK. Safety data sheet - Sodium nitroprusside dihydrate (Catalogue $\mathbf{N}^{\mathrm{o}}$ 106541), 2012.

NRIAGU, J. O.; NIEBOER, E. Chromium in the natural and human environments. Ontario, ON: Wiley Inter-Science, 1988. 571p.

OLIVAS, R. M. et al. Analytical techniques applied to the speciation of selenium in environmental matrices. Analytica Chimica Acta, v. 286, p. 357-370, 1994.

ORGANIZAÇÃO DAS NAÇÕES Unidas (ONU). Rio+20 Conferência das Nações Unidas sobre Desenvolvimento Sustentável. 2012. Disponível em: <www.onu. org.br/rio20/> . Acesso em: 13 mar. 2013. 
PANSU, M.; GAUTHERYOU, J. Handbook of soil analysis: Mineralogical, organic and inorganic methods. Maur des Fossés: Springer, 2003. 993p.

PATTON, C. J.; CROUCH, S. R. Spectrophotometeric and kinetics investigation of the Berthelot reaction for determination of ammonia. Analytical Chemistry, v. 49, p. 464-469, 1977.

PELGROM, S. M. G. J. et al. Interactions between copper and cadmium during single and combined exposure in juvenile tilapia Oreochromis mossambicus: Influence of feeding condition on whole body metal accumulation and the effect of the metals on tissue water and ion content. Aquatic Toxicology, v. 30, n. 2, p. 117-135, 1994.

PENATTI, F. E.; GUIMARÃES, S. T. L.; SILVA, P. M. Gerenciamento de resíduos químicos em laboratórios de análises e pesquisa: o desenvolvimento do sistema em laboratórios da área química. In: WORKSHOP INTERNACIONAL EM INDICADORES DE SUSTENTABILIDADE-WIPIS, 2., 2008. Anais... São Carlos, 2008.

PRADO, A. G. S. Química Verde, os desafios da química do novo milênio. Química Nova, v. 26, p. 738-744, 2003.

PURCELL, L. C.; KING, C. A. Total Nitrogen determination in plant-material by persulfate digestion. Agronomy journal, v. 88, n. 1, p. 111-113, 1996.

REINHARDT, P. A. et al. Pollution, prevention and waste minimization in laboratories. Boca Raton: CRC Press, 1996. 480p.

SEMARH. Secretaria de Estado do Meio Ambiente e dos Recursos Hídricos. Instrução Normativa $\mathbf{n}^{0} \mathbf{0 7}$, de 10 de agosto de 2011. Dispõe sobre gerenciamento e disposição final dos resíduos sólidos gerados em unidades de produção industrial, de bens e serviços. Goiania, 2011.

SHINN, M. B. Colorimetric method for determination of nitrite. Engineering Chemistry Analytical Edition, v. 13, p. 33-35, 1941.

SILVA, F. C. Manual de Análises Químicas de Solos, Plantas e Fertilizantes. 2. ed. Brasília: Embrapa Comunicação para Transferência de Tecnologia, 2009. 627p. 
SILVA, F. M. et al. Desenvolvimento sustentável e Química Verde. Química Nova, v. 28, n. 1, p. 103-110, 2005.

SILVA, V. S. et al. O destino do bagaço da cana-de-açúcar: um estudo a partir das agroindústrias sucroalcooleiras do Paraná. Revista em Agronegócio e Meio Ambiente, v. 3, n. 1, 2010.

SOUZA, A. F.; ROSADO, F. R. Utilização de fungos Basidiomicetes em biodegradação de efluentes têxteis. Revista em Agronegócio e Meio Ambiente, v. 2, n. 1, p. 121139, 2009.

SOUZA, D. M. et al. Aplicação de métodos quimiométricos na otimização da extração de $\mathrm{Ca}, \mathrm{Mg}, \mathrm{K}, \mathrm{Fe}, \mathrm{Zn}, \mathrm{Cu}$ e Mn em folhas de braquiária. Química Nova, v. 35, n. 1, p. 175-179, 2012.

SOUZA, D. M. et al. Aplicação de técnicas multivariadas e inteligência artificial na análise de espectros de infravermelho para determinação de matéria orgânica em amostras de solo. Química Nova, v. 35, n. 9, 1738-1745, 2012.

VERDOUW, H. et al. Ammonia determination based on indophenol formation with sodium salicylate. Water Research, v. 12, n. 6, p. 399-402, 1978.

VOGEL, A. I. Química Analítica Qualitativa. 5. ed. São Paulo: Mestre Jou, 1985. $665 \mathrm{p}$.

WALKLEY, A.; BLACK, I. A. An Examination of Degtjareff Method for Determining Soil Organic Matter and a Proposed Modification of the Chromic Acid Titration Method. Soil Science, v. 37, p. 29-37, 1934.

WILLIS, R. B. et al. Improved method for manual, colorimetric determination of total Kjeldahl nitrogen using salicylate. Journal of Agricultural Food Chemistry, v. 44, p. 1804-1807, 1996.

Recebido: 10 de julbo de 2015

Aceito: 18 de agosto de 2015 